Supporting Information

\title{
Conjugated Crosslinked Phenothiazines as Green or Red Light Heterogeneous Photocatalysts for Copper-Catalyzed Atom Transfer Radical Polymerization
}

Sajjad Dadashi-Silab, ${ }^{a}$ Francesca Lorandi, ${ }^{a}$ Matthew J. DiTucci, ${ }^{b}$ Mingkang Sun, ${ }^{a}$ Grzegorz Szczepaniak, ${ }^{a}$ Tong Liu, ${ }^{a}$ Krzysztof Matyjaszewski ${ }^{a *}$

${ }^{a}$ Department of Chemistry, Carnegie Mellon University, 4400 Fifth Avenue, Pittsburgh, Pennsylvania 15213, United States

${ }^{b}$ PPG Coatings Innovation Center, 4325 Rosanna Drive, Allison Park, Pennsylvania 15101, United States

*Email: $\underline{\text { matyjaszewski@cmu.edu }}$ 


\section{EXPERIMENTAL}

\section{Materials}

Phenothiazine (PTZ; Sigma-Aldrich, 98\%), bromobenzene (TCI, 99\%), RuPhos (2dcyclohexylphosphino-2',6'-diisopropoxybiphenyl; Sigma-Aldrich, 95\%), RuPhos Pd G2 (chloro(2-dicyclohexylphosphino-2',6'-diisopropoxy-1,1'-biphenyl)[2-(2'-amino-1,1'-biphenyl)] palladium(II); Sigma-Aldrich) were used as received. Methyl acrylate (MA; Sigma-Aldrich, 99\%), n-butyl acrylate (BA; Acros Organics, 99\%), (2-methoxyethyl) acrylate (MEA; TCI, > 98.0), 2,2,2-trifluoroethyl acrylate (TFEA; TCI, >98.0), and methyl methacrylate (MMA, SigmaAldrich, 99\%) were passed through a column of basic alumina to remove polymerization inhibitor prior to use. Ethyl $\alpha$-bromoisobutyrate (EBiB; Sigma-Aldrich, 98\%), ethyl $\alpha$-bromophenylacetate (EBPA; Sigma-Aldrich, 97\%), $N, N, N^{\prime}, N^{\prime \prime}, N^{\prime \prime}$-pentamethyldiethylenetriamine (PMDETA; SigmaAldrich, 98\%), tris(2-pyridylmethyl)amine (TPMA; AmBeed), copper(II) bromide ( $\mathrm{CuBr}$; Sigma-Aldrich, 99\%), iron(III) chloride ( $\mathrm{FeCl}_{3}$, anhydrous; Sigma-Aldrich, 97\%), dimethyl sulfoxide (DMSO), N,N-dimethylformamide (DMF), and acetonitrile $(\mathrm{MeCN})$, dioxane (anhydrous), and nitrobenzene were used as received. Tris[2-(dimethylamino)ethyl]amine (Me6TREN) was received from Koei Chemical Co., Ltd. (Japan).

\section{Instrumentation}

${ }^{1} \mathrm{H}$ nuclear magnetic resonance ( ${ }^{1} \mathrm{H}$ NMR) measurements were performed on a Bruker Avance ${ }^{\mathrm{TM}}$ III $500 \mathrm{MHz}$ spectrometer. Molecular weight properties of the polymers were determined by sizeexclusion chromatography (SEC). The SEC instrument was equipped with a Waters 515 pump and a Waters 2414 differential refractometer using PSS columns (SDV 10 $10^{5}$, and $500 \AA \AA$ ) with THF as eluent at $35^{\circ} \mathrm{C}$ and a flow rate of $1 \mathrm{~mL} \mathrm{~min}^{-1}$. Linear poly(methyl methacrylate) standards were used for calibration.

Nitrogen sorption was conducted using a Nava 3200e porosity and surface analyzer. The samples were heated in vacuum at $120{ }^{\circ} \mathrm{C}$ overnight $(16 \mathrm{~h})$ prior to $\mathrm{N}_{2}$ sorption analysis in $77 \mathrm{~K}$. The Brunauer-Emmett-Teller (BET) method was used to determine the surface area. The pore size distribution was calculated using the Barrett-Joyner-Halenda (BJH) method.

Scanning electron microscope (SEM) was performed for microstructural investigation and conducted on a Quanta 600 FEG instrument. Samples for SEM characterization were prepared by distributing the photocatalyst powder onto electrical tape substrate. 
The electrochemical analysis was performed in a 7-neck electrochemical cell, equipped with a 3electrode system, and connected to an Autolab PGSTAT302N potentiostat/galvanostat (Metrohm) run by a PC with NOVA 2.0 software. The 3-electrode system composed of: i) a Pt foil counter electrode; ii) a saturated calomel electrode (SCE) as reference electrode; iii) a glassy carbon (GC) disk tip ( $3 \mathrm{~mm}$ dia., Metrohm), connected to a rotating disk electrode (RDE) system, as working electrode. Before each experiment, the GC disk was cleaned by polishing with a $0.25-\mu \mathrm{m}$ diamond paste, followed by ultrasonic rinsing in ethanol for $5 \mathrm{~min}$. The electrochemical cell was placed at the center of a green LED photoreactor. The analyses were performed under inert atmosphere $\left(\mathrm{N}_{2}\right)$. An initial cyclic voltammetry of the sole PTZ-CMP photocatalyst in DMSO as solvent and 0.1 M $\mathrm{Et}_{4} \mathrm{NBF}_{4}$ as supporting electrolyte was recorded. No signal corresponding to redox processes involving the photocatalysts could be observed in the electrochemical window. Subsequently, $\mathrm{CuBr}_{2}$ and PMDETA $(\mathrm{L} / \mathrm{Cu}=6)$ were added into the system and an initial linear sweep voltammetry (LSV) was recorded. Then, the light was turned on consecutive LSVs were recorded to monitor the evolution in the currents corresponding to the $\mathrm{Cu}$ complex.

Diffuse reflectance UV-Vis-NIR spectra were acquired using a Perkin Elmer Lambda 950 spectrophotometer with $150 \mathrm{~mm}$ integration sphere and specular port removed. $\mathrm{BaSO}_{4}$ (Bafine BF20, KOWA American Corp.) was pressed into an $8 \mathrm{~mm}$ depth, $2.5 \mathrm{~cm}$ diameter powder plate and used as the $100 \% \mathrm{R}$ reference in all measurements. Neat PTZ-CMP was prepared over the $\mathrm{BaSO}_{4}$ surface in triplicate with increasing mass from 10,20 , and $30 \mathrm{mg}$ to evaluate and ensure onset of a pseudo-infinite medium for reflectance. Spectra were transformed to Kubelka-Munk, $\mathrm{F}\left(\mathrm{R}_{\text {inf }}\right)$, values and used in generation of Tauc plots (resulting in $\left(h v \mathrm{~F}\left(\mathrm{R}_{\text {inf }}\right)\right)^{1 / \mathrm{n}}$ vs. $h v$ and assuming the PTZ-CMP electronic transition is direct allowed, $n=1 / 2$ ). Inflection points at $\sim 2.4 \mathrm{eV}$ were identified via first derivatives and used to define the onset of linearity. Fitting this linear region to evaluate intersection of the abscissa for each spectrum resulted in an average band gap energy, $E_{\mathrm{g}}=2.23+/-0.02 \mathrm{eV}(\sim 556 \mathrm{~nm})$.

Polymerizations were irradiated under green $\left(\lambda_{\max }=520 \mathrm{~nm}, 9 \mathrm{~mW} / \mathrm{cm}^{2}\right)$ and red $\left(\lambda_{\max }=630 \mathrm{~nm}\right.$, $4 \mathrm{~mW} / \mathrm{cm}^{2}$ ) LEDs purchased from aspectLED or red LED lamps (powerPAR, $\lambda_{\max }=660 \mathrm{~nm}, 40$ $\mathrm{mW} / \mathrm{cm}^{2}$ ). The LED strips were mounted inside a glass container (diameter $=9 \mathrm{~cm}$, height $=7 \mathrm{~cm}$ ) and a cooling fan was used during polymerization to maintain the reactions at room temperature. 


\section{Synthetic procedures}

Synthesis of Ph-PTZ

Phenothiazine (5 g, 25 mmol, 1 equiv.), RuPhos (467.5 mg, 4 mol\%), RuPhos Pd G2 (777 mg, 4 $\mathrm{mol} \%$ ), and $\mathrm{KtBuO}$ (5.62 g, 2 equiv.) were charged into a Schlenk flask equipped with a stirrer bar. The flask was subject to vacuum and backfilling with nitrogen for 5 times. Anhydrous dioxane $(20 \mathrm{~mL})$ was added to the reaction and the flask was placed in an oil bath at $110{ }^{\circ} \mathrm{C}$ overnight. The reaction was cooled to room temperature, diluted with dichloromethane, and washed with water and brine and dried over sodium sulfate. The content was further purified by column chromatography $($ EtOAc/hexanes $=5 / 95)$ to yield $4.9 \mathrm{~g}$ of the product in $75 \%$ yield. ${ }^{1} \mathrm{H}$ NMR $(500$ $\left.\mathrm{MHz}, \mathrm{CDCl}_{3}\right) \delta: 7.62(\mathrm{t}, 2 \mathrm{H}), 7.49(\mathrm{t}, 1 \mathrm{H}), 7.41(\mathrm{~d}, 2 \mathrm{H}), 7.03(\mathrm{~d}, 2 \mathrm{H}), 6.87-6.80(\mathrm{~m}, 4 \mathrm{H}), 6.21(\mathrm{~d}$, $2 \mathrm{H}) \mathrm{ppm}$ (Figure S15).

Synthesis of PTZ-CMP

Ph-PTZ (200 mg, 0.72 mmol, 1 equiv.), dimethoxybenzene (800 mg, 5.76 mmol, 8 equiv.), and $\mathrm{FeCl}_{3}$ (2.8 g, $17.28 \mathrm{mmol}, 24$ equiv.) were charged into a Schlenk flask followed by addition of nitrobenzene under nitrogen atmosphere. The flask was placed in an oil bath and was heated at 80 ${ }^{\circ} \mathrm{C}$ for $4 \mathrm{~h}$ after which the temperature was increased to $120^{\circ} \mathrm{C}$ to allow complete formation of the network for $20 \mathrm{~h}$. After the reaction, the precipitate was extensively washed with acetone, THF, and methanol until the filtrate became clear. The network was further washed by stirring the dispersion in DMSO, DMF, and MeCN multiple times overnight. Finally, the network was filtered and allowed to dry under vacuum to yield $\sim 470 \mathrm{mg}$ of the PTZ-CMP in dark brown color.

\section{General procedure for photoinduced ATRP using PTZ-CMP}

The photocatalyst PTZ-CMP (1-4 mg) was added to a 2-dram reaction vial. The vial equipped with a magnet bar was sealed with a rubber septum and subjected to vacuum and backfilled with nitrogen for 5 times. In separate vials, DMSO and MA were degassed with nitrogen for $30 \mathrm{~min}$. Under nitrogen atmosphere, DMSO $(1 \mathrm{~mL})$, and a stock solution of $\mathrm{CuBr}_{2}(0.5 \mathrm{mg}, 2.2 \mu \mathrm{mol}, 0.04$ equiv.), and PMDETA $(2.3 \mu \mathrm{L}, 11 \mu \mathrm{mol}, 0.2$ equiv.) in DMSO $(50 \mu \mathrm{L})$ was added followed by the addition of MA ( $1 \mathrm{~mL}, 11.1 \mathrm{mmol}, 200$ equiv.) and $\mathrm{EBiB}(8.14 \mu \mathrm{L}, 55.5 \mu \mathrm{mol}, 1$ equiv. $)$ under nitrogen. The vial was degassed further with nitrogen for 2 min and was then irradiated under 
green LEDs to start the polymerization. Samples were taken periodically and analyzed by ${ }^{1} \mathrm{H}$ NMR and SEC to determine the monomer conversion and molecular weight properties, respectively.

Procedure for photoinduced ATRP of MMA using PTZ-CMP

The photocatalyst PTZ-CMP ( $8 \mathrm{mg})$ was added to a 2 -dram reaction vial. The vial equipped with a magnet bar was sealed with a rubber septum and subjected to vacuum and backfilled with nitrogen for 5 times. In separate vials, DMSO and MMA were degassed with nitrogen for $30 \mathrm{~min}$. Under nitrogen atmosphere, DMSO $(2 \mathrm{~mL})$, and a stock solution of $\mathrm{CuBr}_{2}(0.84 \mathrm{mg}, 3.7 \mu \mathrm{mol}$, 0.04 equiv.), and PMDETA (3.92 $\mu \mathrm{L}, 18.8 \mu$ mol, 0.2 equiv.) in DMSO (50 $\mu \mathrm{L}$ ) was added followed by the addition of MMA ( $2 \mathrm{~mL}, 18.8 \mathrm{mmol}, 200$ equiv.) and EBPA ( $16.4 \mu \mathrm{L}, 94 \mu \mathrm{mol}$, 1 equiv.) under nitrogen. The vial was degassed further with nitrogen for 2 min and was then irradiated under green LEDs to start the polymerization. Samples were taken periodically and analyzed by ${ }^{1} \mathrm{H}$ NMR and SEC to determine the monomer conversion and molecular weight properties, respectively.

\section{Procedure for recycling the PTZ-CMP photocatalyst}

The photocatalyst PTZ-CMP (4 mg) was added to a 2-dram reaction vial. The vial equipped with a magnet bar was sealed with a rubber septum and subjected to vacuum and backfilled with nitrogen for 5 times. In separate vials, $\mathrm{MeCN}$ and MA were degassed with nitrogen for $30 \mathrm{~min}$. Under nitrogen atmosphere, $\mathrm{MeCN}(1 \mathrm{~mL})$, and a stock solution of $\mathrm{CuBr}_{2}(0.5 \mathrm{mg}, 2.2 \mu \mathrm{mol}, 0.04$ equiv.), and $\mathrm{Me}_{6}$ TREN ( $3 \mu \mathrm{L}, 11 \mu \mathrm{mol}, 0.2$ equiv.) in $\mathrm{MeCN}(50 \mu \mathrm{L})$ was added followed by the addition of MA ( $1 \mathrm{~mL}, 11.1 \mathrm{mmol}, 200$ equiv.) and $\mathrm{EBiB}(8.14 \mu \mathrm{L}, 55.5 \mu \mathrm{mol}, 1$ equiv.) under nitrogen. The vial was degassed further with nitrogen for $2 \mathrm{~min}$ and was then irradiated under green LEDs to start the polymerization. After $18 \mathrm{~h}$, samples were analyzed by ${ }^{1} \mathrm{H}$ NMR and SEC to determine the monomer conversion and molecular weight properties, respectively. The mixture was diluted by adding $8 \mathrm{~mL}$ of $\mathrm{MeCN}$ and the photocatalyst was separated by centrifugation. The photocatalyst was thoroughly washed with $\mathrm{MeCN}$ and separated by centrifugation for 5 times and dried before use in the next cycle. A fresh solution of $\mathrm{CuBr}_{2} / \mathrm{Me}_{6} \mathrm{TREN}$ was used in each cycle. 

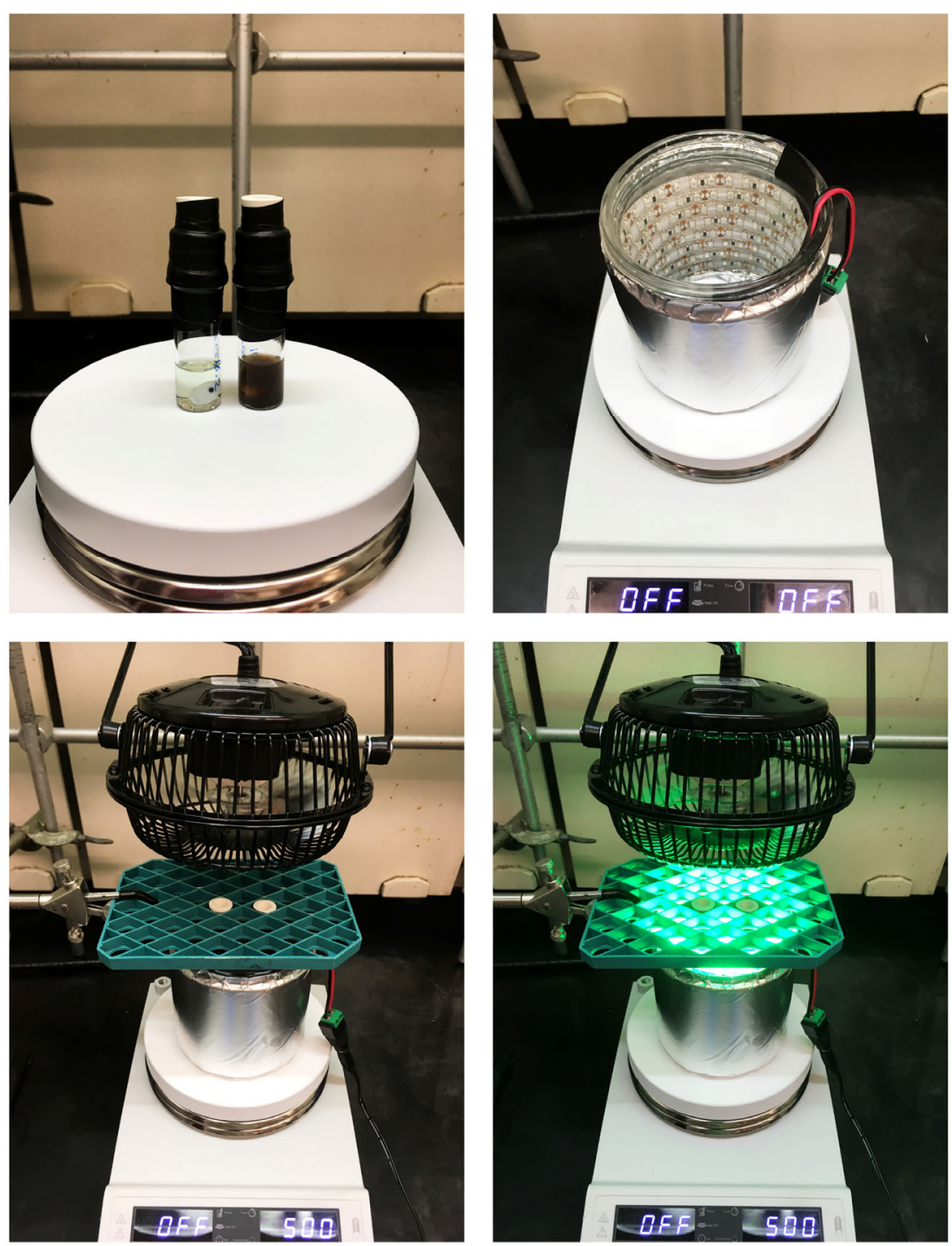

Figure S1. Photoreactor setup used in polymerization reactions. Top-left: pictures of polymerization reactions with (right vial) and without (left vial) the PTZ-CMP photocatalyst. Top-right: picture of the photoreactor with green LED strips installed inside a glass container. Bottom: reaction vials irradiated under green light with a colling fan placed on top to maintain the reaction at room temperature. 

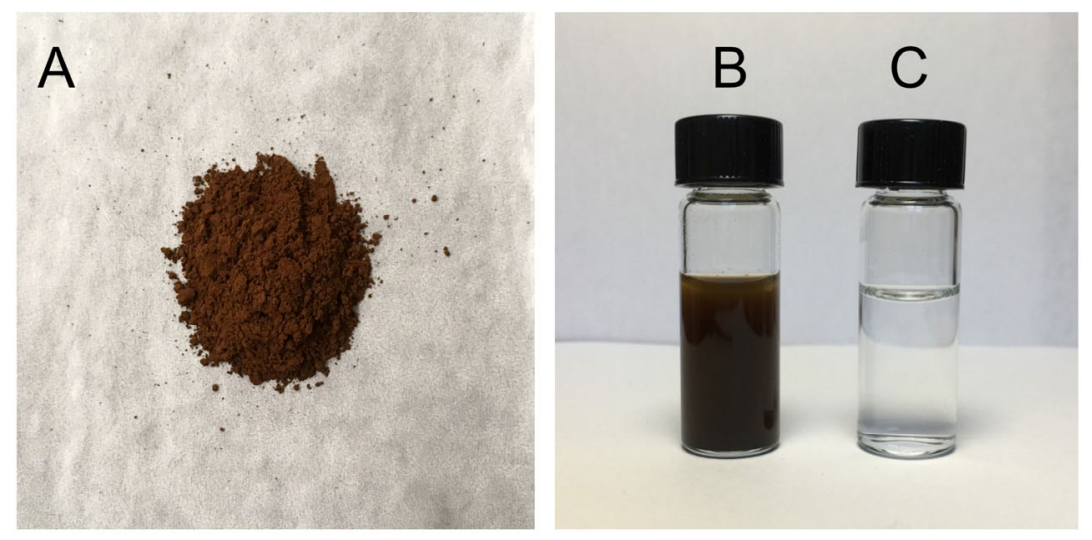

Figure S2. Images of PTZ-CMP in (A) powder form, (B) dispersed in $\mathrm{MeCN}$, and (C) after filtration of the dispersion in $\mathrm{MeCN}$ through syringe filters.
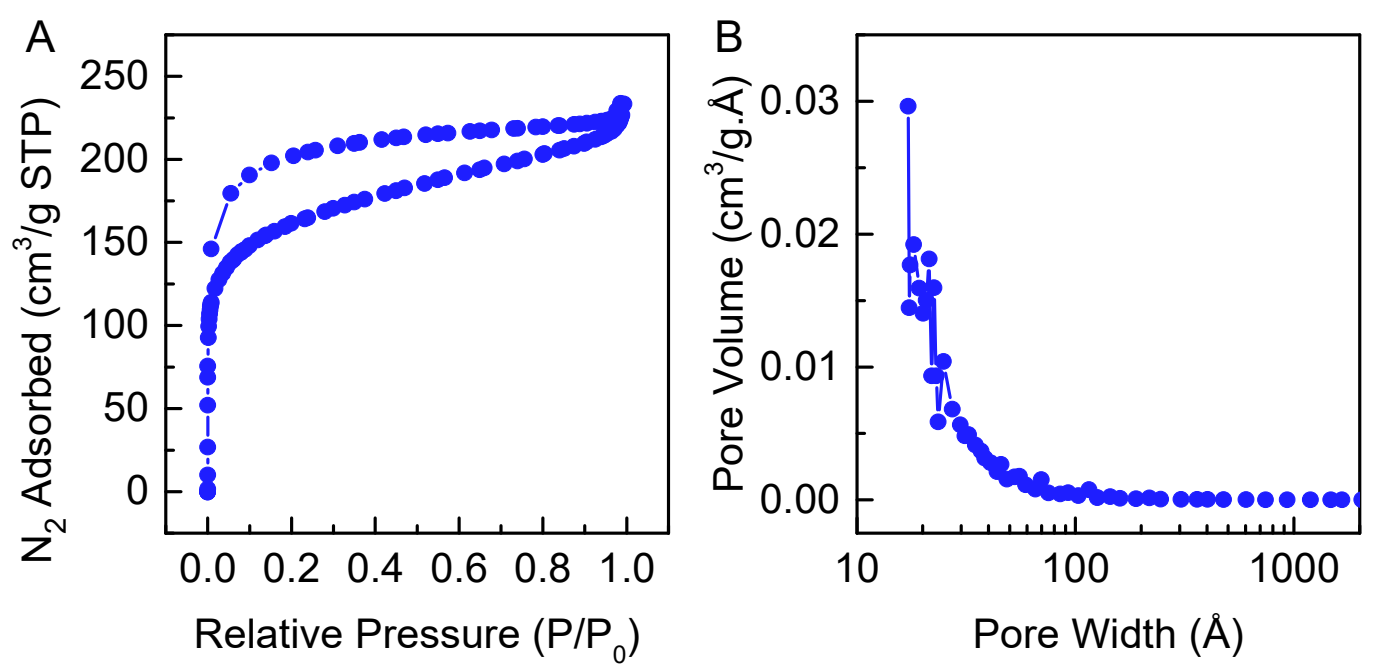

Figure S3. Nitrogen sorption isotherms of BET surface area analysis of the PTZ-CMP polymers and $(\mathrm{C})$ corresponding pore size distribution. 


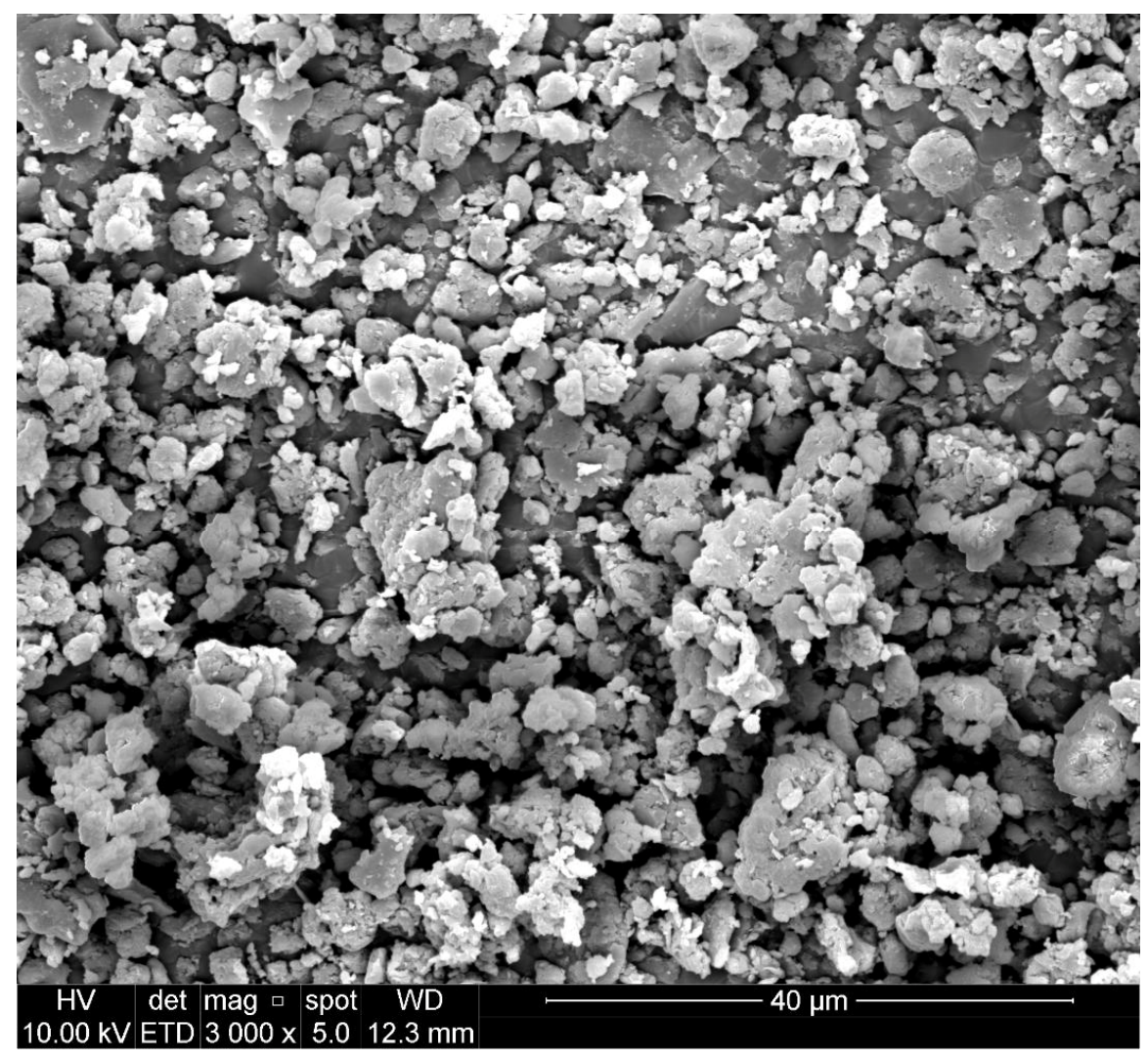

Figure S4. SEM image of the PTZ-CMP photocatalyst. 

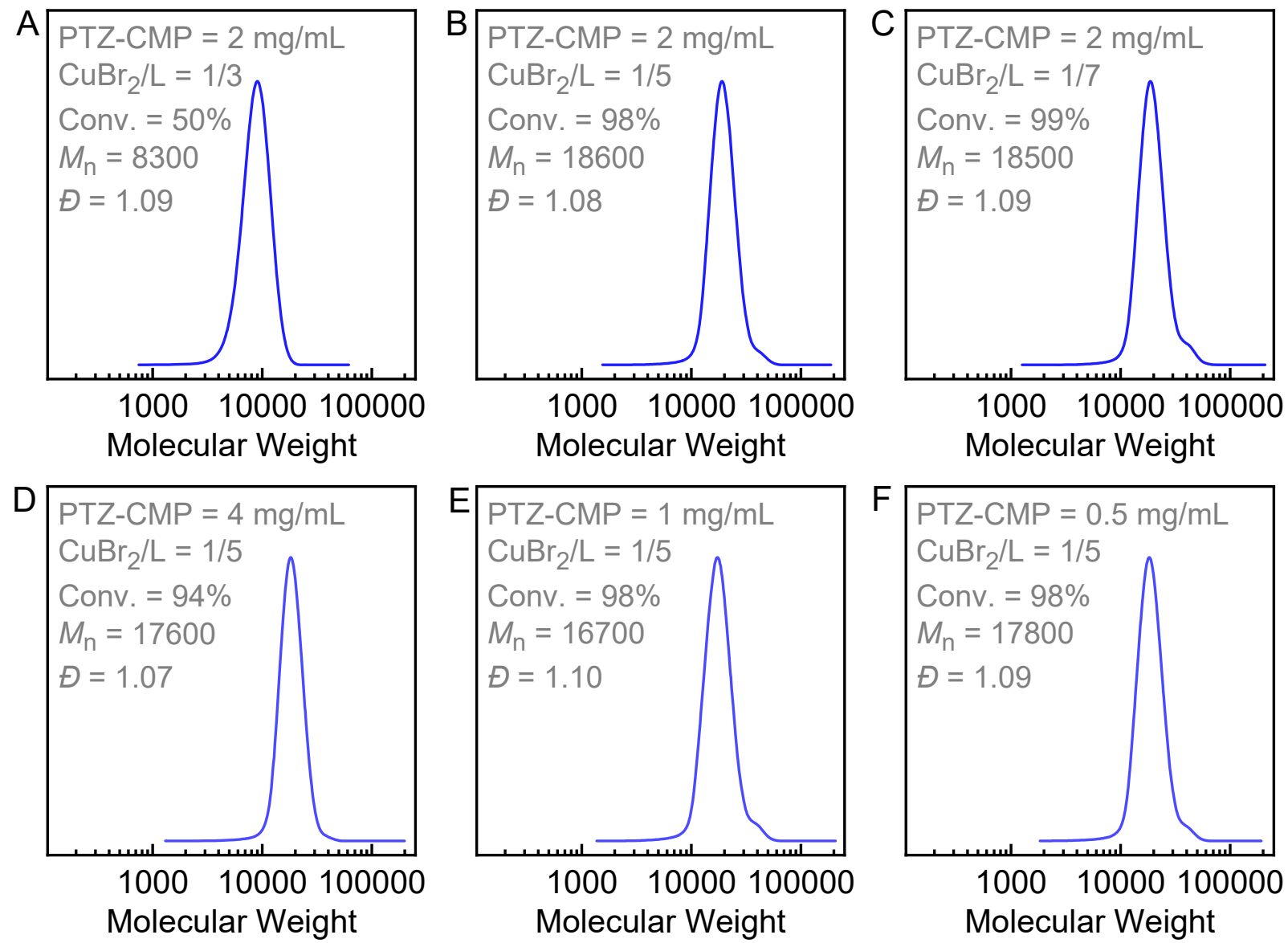

Figure S5. SEC traces of PMA synthesized using PTZ-CMP as a heterogeneous photocatalyst showing the effect of increasing concentration of the excess ligand or the photocatalyst. Conditions: [MA]/[EBiB]/[CuBr 2$] /[\mathrm{PMDETA}]=200 / 1 / 0.04 / \mathrm{x}(\mathrm{x}=$ $0.12,0.20$, or 0.28$)$ in DMSO (50 vol\%), PTZ-CMP $=0.5,2$, or $4 \mathrm{mg} / \mathrm{mL}$ irradiated under green light for $24 \mathrm{~h}$. 

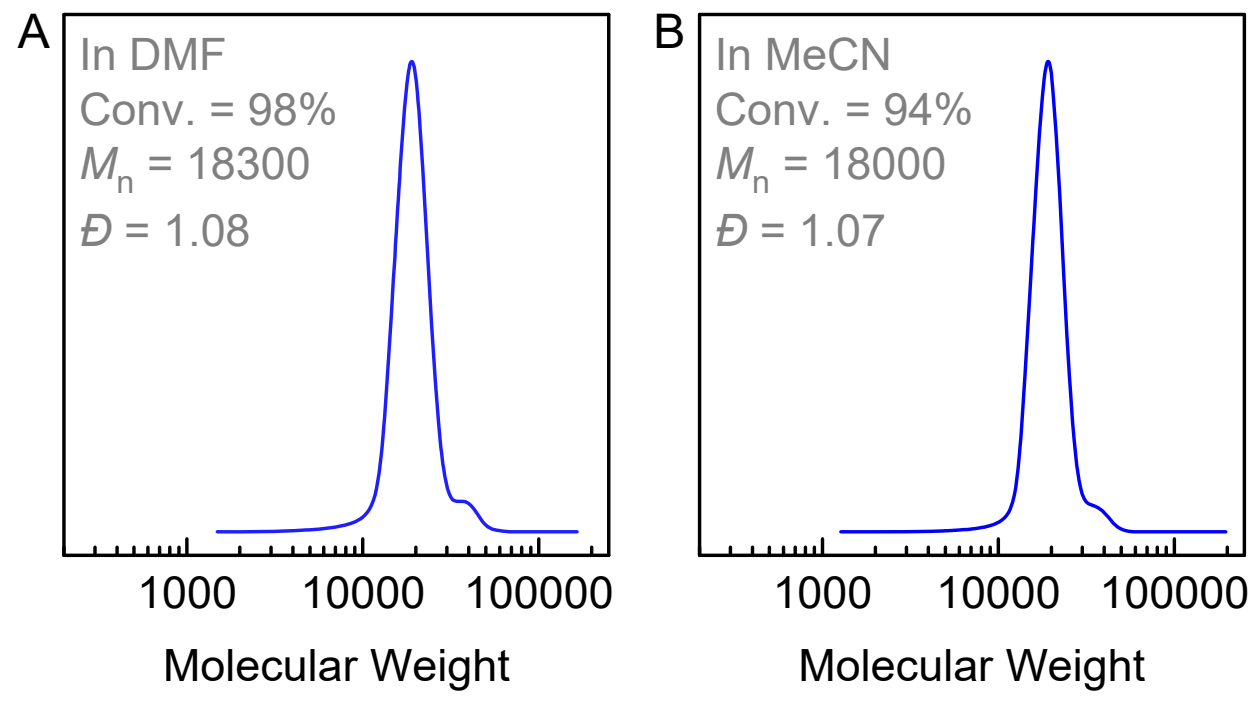

Figure S6. SEC traces of PMA synthesized using PTZ-CMP as a heterogeneous photocatalyst in $\mathrm{DMF}$ or MeCN. Reaction conditions: [MA]/[EBiB] $/\left[\mathrm{CuBr}_{2}\right] /\left[\mathrm{Me}_{6} \mathrm{TREN}\right]=$ 200/1/0.04/0.2 in DMF or MeCN (50 vol\%), PTZ-CMP $=2 \mathrm{mg} / \mathrm{mL}$ irradiated under green light for $24 \mathrm{~h}$. 
ATRP under red light:

Table S1.Polymerization of MA using heterogeneous PTZ-CMP photocatalyst under red light irradiation $^{a}$

\begin{tabular}{|c|c|c|c|c|c|c|c|}
\hline Entry & Light source & Ligand & PTZ-CMP $(\mathrm{mg} / \mathrm{mL})$ & Conv. $(\%)$ & $M_{\mathrm{n}, \mathrm{th}}$ & $M_{\mathrm{n}}$ & 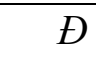 \\
\hline 1 & $630 \mathrm{~nm}-4 \mathrm{~mW} / \mathrm{cm}^{2}$ & PMDETA & 2 & 0 & - & - & - \\
\hline 2 & & PMDETA & 4 & 0 & - & - & - \\
\hline 3 & & $\mathrm{Me}_{6} \mathrm{TREN}$ & 0 & 0 & - & - & - \\
\hline 4 & & $\mathrm{Me}_{6} \mathrm{TREN}$ & 2 & 0 & - & - & - \\
\hline 5 & $660 \mathrm{~nm}-40 \mathrm{~mW} / \mathrm{cm}^{2}$ & PMDETA & 2 & 84 & 14700 & 16000 & 1.07 \\
\hline 6 & & $\mathrm{Me}_{6} \mathrm{TREN}$ & 0 & 0 & - & - & - \\
\hline 7 & & $\mathrm{Me}_{6}$ TREN & 2 & 40 & 7000 & 6600 & 1.07 \\
\hline
\end{tabular}

${ }^{a}$ Reaction conditions: $[\mathrm{MA}] /[\mathrm{EBiB}] /\left[\mathrm{CuBr}_{2}\right] /[\mathrm{L}]=200 / 1 / 0.04 / 0.2$ in $50 \mathrm{vol} \%$ solvent (DMSO or

MeCN used with PMDETA or $\mathrm{Me}_{6}$ TREN ligands, respectively) under red light irradiation (630 $\mathrm{nm}, 4 \mathrm{~mW} / \mathrm{cm}^{2}$ or $660 \mathrm{~nm}, 40 \mathrm{~mW} / \mathrm{cm}^{2}$ ) for $24 \mathrm{~h}, \mathrm{PTZ}-\mathrm{CMP}=2$ or $4 \mathrm{mg} / \mathrm{mL}$.
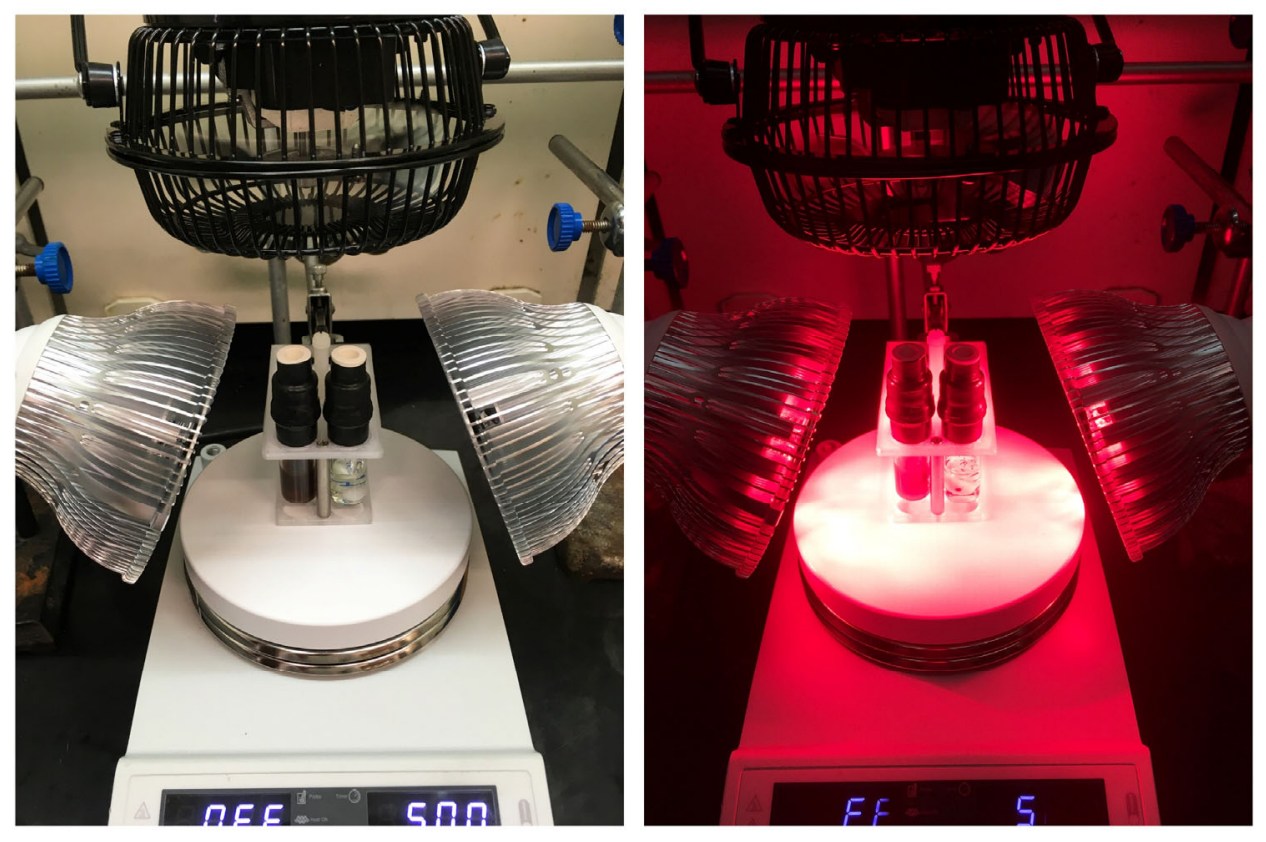

Figure S7. Setup used for polymerizations conducted under red LED lamps (660 nm, 40 $\mathrm{mW} / \mathrm{cm}^{2}$ ). Reaction vials show ATRP experiments performed in the presence (left vial) or absence (right vial) of the PTZ-CMP photocatalyst in MeCN. 
Kinetics and temporal control:
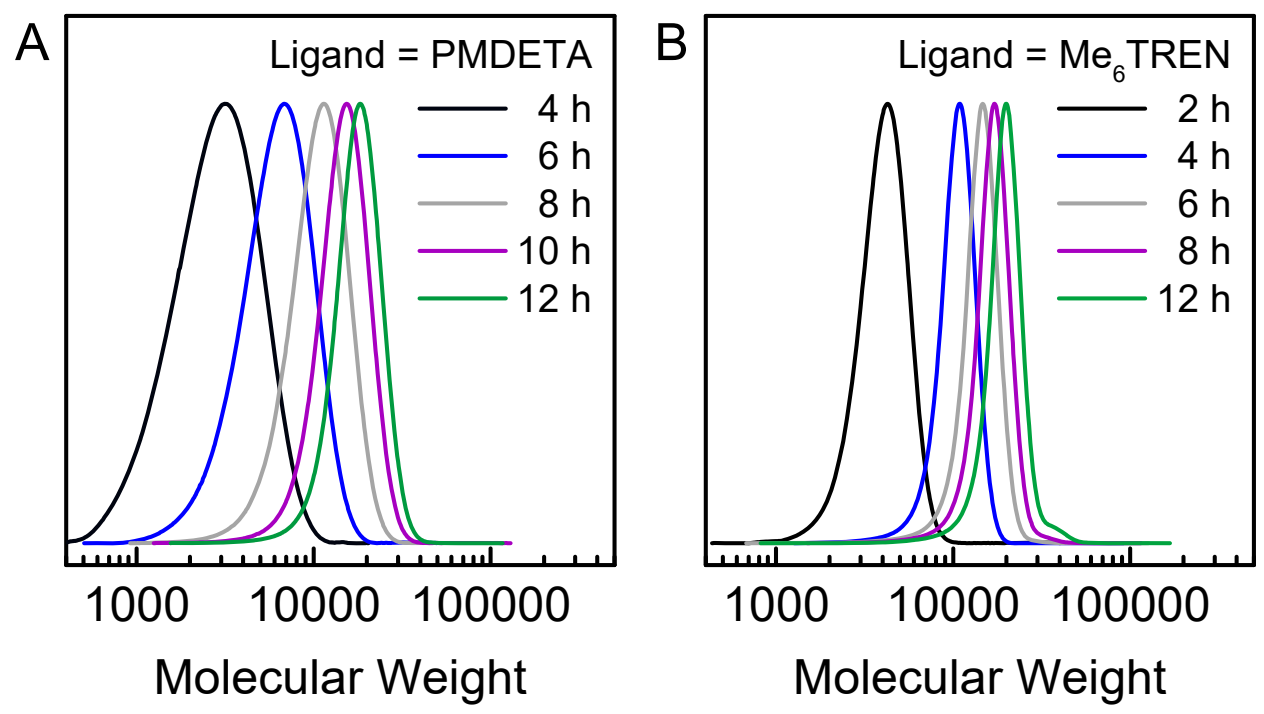

Figure S8. Evolution of GPC traces of PMA synthesized by ATRP using PTZ-CMP photocatalyst in the presence of (A) PMDETA or (B) Me ${ }_{6}$ TREN ligands. Reaction conditions: $[\mathrm{MA}] /[\mathrm{EBiB}] /\left[\mathrm{CuBr}_{2}\right] /[\mathrm{L}]=200 / 1 / 0.04 / 0.2, \mathrm{~L}=$ PMDETA or Me $6 \mathrm{TREN}$ in $50 \mathrm{vol} \%$ DMSO or MeCN, respectively, irradiated under green light LEDs. 

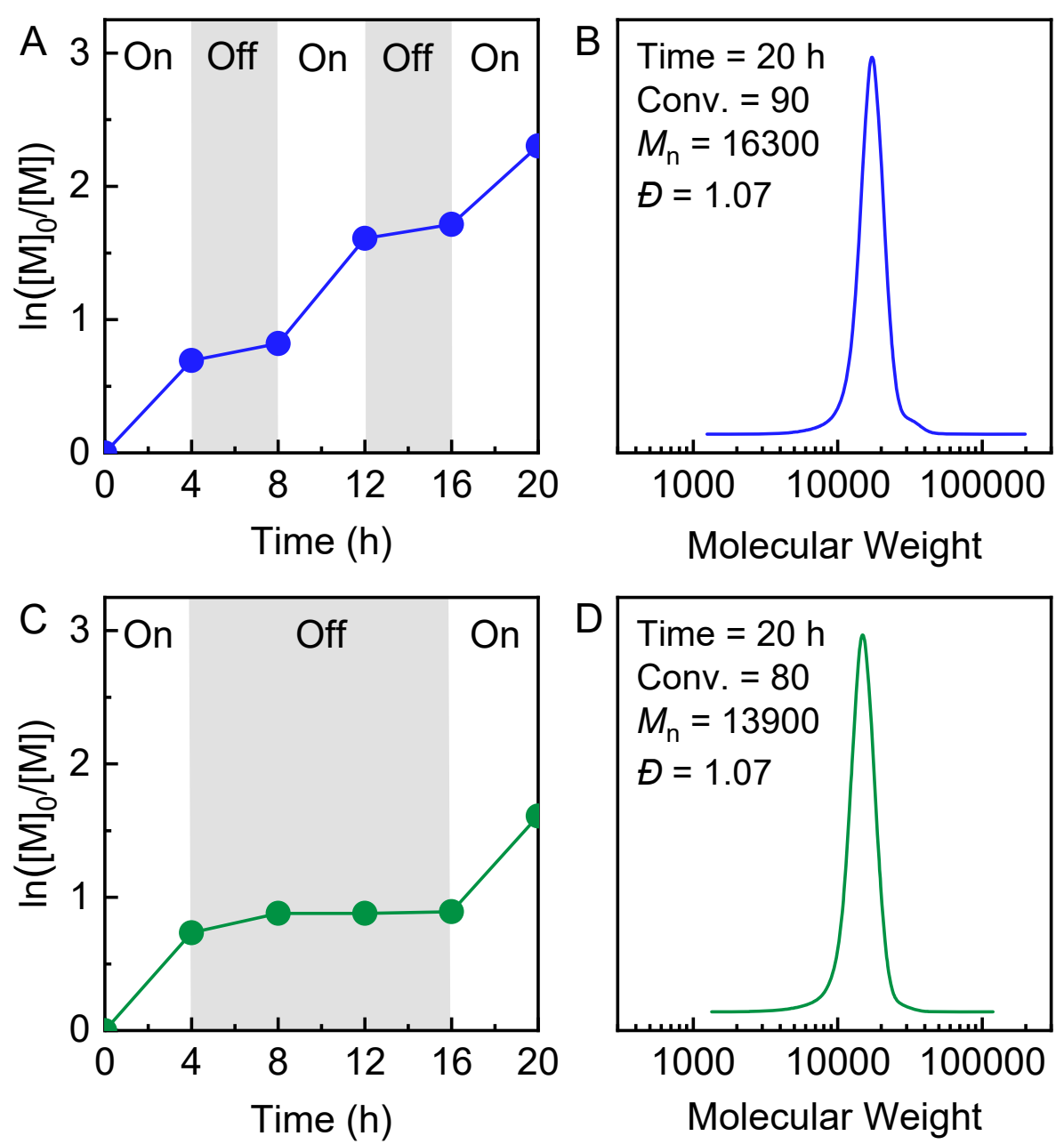

Figure S9. (A) and (C) Kinetics of temporal control in ATRP of MA and (B) and (D) corresponding GPC traces of the resulting polymers after intermittent light on/off periods. Reaction conditions: $[\mathrm{MA}] /[\mathrm{EBiB}] /\left[\mathrm{CuBr}_{2}\right] /\left[\mathrm{Me}_{6} \mathrm{TREN}\right]=200 / 1 / 0.04 / 0.2$ in $\mathrm{MeCN}$ (50 vol\%), PTZ-CMP = $2 \mathrm{mg} / \mathrm{mL}$ irradiated under green light LEDs. 
Effect of the Cu catalyst:

Table S2. Results of control experiments in polymerization of MA using PTZ-CMP as a heterogeneous photocatalyst in the absence of the $\mathrm{Cu}$ catalyst ${ }^{a}$

\begin{tabular}{llrrrrr}
\hline Entry & {$[\mathrm{EBiB}] /[\mathrm{CuBr} 2] /[\mathrm{PMDETA}]$} & Time (h) & Conv. (\%) & $M_{\mathrm{n}, \text { th }}$ & $M_{\mathrm{n}}$ & $D$ \\
\hline 1 & $0 / 0 / 0$ & 24 & 0 & - & - & - \\
2 & $1 / 0 / 0$ & 24 & 0 & - & - & - \\
3 & $0 / 0 / 0.2$ & 3 & 12 & - & 650000 & 1.91 \\
4 & $1 / 0.04 / 0.04$ & 24 & 0 & - & - & - \\
5 & $1 / 0.04 / 0.2$ & 24 & 98 & 17100 & 18600 & 1.08
\end{tabular}

${ }^{a}$ Reaction conditions: [MA] $=200$ equiv. in DMSO (50 vol\%) under green light irradiation (520 $\mathrm{nm}, 9 \mathrm{~mW} / \mathrm{cm}^{2}$ ) for $24 \mathrm{~h}, \mathrm{PTZ}-\mathrm{CMP}=2 \mathrm{mg} / \mathrm{mL}$.

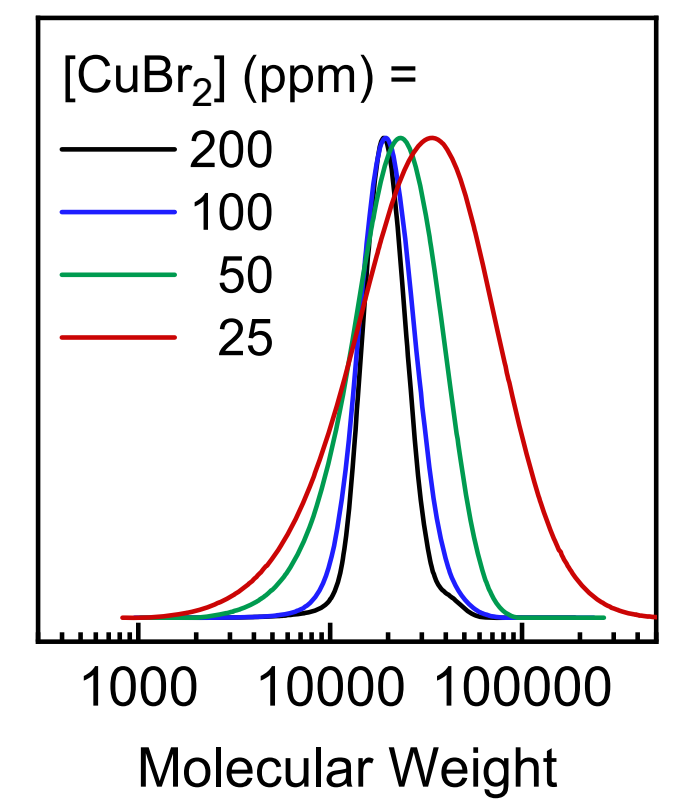

Figure S10. SEC traces of PMA synthesized in the presence of decreasing concentration of the $\mathrm{Cu}$ catalyst with PMDETA ligand. Reaction conditions: $[\mathrm{MA}] /[\mathrm{EBiB}] /\left[\mathrm{CuBr}_{2}\right] /[\mathrm{PMDETA}]=200 / 1 / \mathrm{x} / 0.2(\mathrm{x}=0.04,0.02,0.01$, and 0.005 equiv. with respect to initiator corresponding to $200,100,50$, and $25 \mathrm{ppm}$ with respect to monomer) in DMSO (50 vol\%) under green light irradiation $\left(520 \mathrm{~nm}, 9 \mathrm{~mW} / \mathrm{cm}^{2}\right)$. 


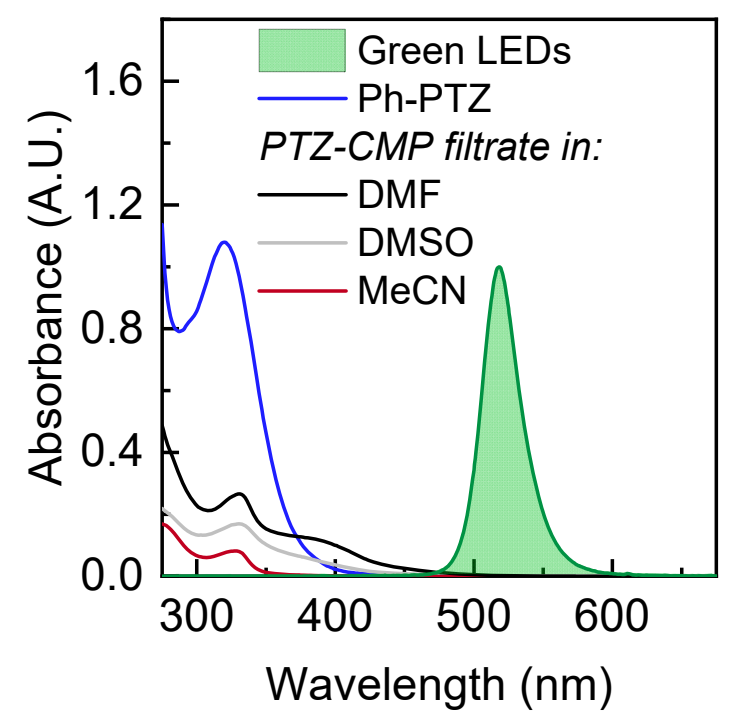

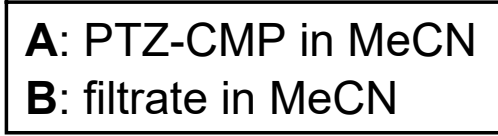

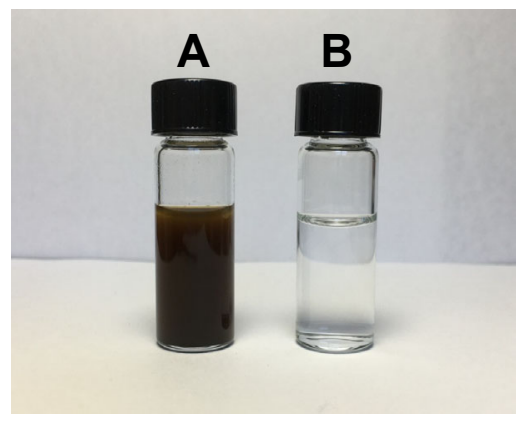

Figure S11. UV-vis spectra of Ph-PTZ and the filtrate of PTZ-CMP dispersed in DMSO, DMF, or MeCN filtered through syringe filters. The UV-vis spectra of the filtrates show absorption in the UV region corresponding to monomeric/oligomeric PTZ photocatalysts dissolved in the solutions that have no overlap with the emission spectra of the LEDs. [Ph-PTZ] $=0.2 \mathrm{mM}(0.055 \mathrm{mg} / \mathrm{mL}$ in DMSO $),[\mathrm{PTZ}-\mathrm{CMP}]=2$ $\mathrm{mg} / \mathrm{mL}$ stirred for $24 \mathrm{~h}$. Right: (A) pictures of a dispersion of PTZ-CMP in MeCN and (B) after filtration through syringe filters $(0.45 \mu \mathrm{m})$ showing complete removal of the heterogeneous photocatalyst.

By comparing the absorbance of the filtrates (maximum at $\sim 330 \mathrm{~nm}$ ) with that of Ph-PTZ $(0.02$ $\mathrm{mM}$, maximum at $320 \mathrm{~nm})$, the concentration of the soluble parts in the PTZ-CMP $(2 \mathrm{mg} / \mathrm{mL})$ for each solvent can be estimated as following:

$[\mathrm{Ph}-\mathrm{PTZ}]=0.2 \mathrm{mM}(0.055 \mathrm{mg} / \mathrm{mL})$

Abs at $320 \mathrm{~nm}=1.09$

PTZ-CMP filtrate in DMSO:

Abs at $330 \mathrm{~nm}=0.17$

$[$ PTZ $]$ soluble $=(0.17 / 1.09) \times(0.055 \mathrm{mg} / \mathrm{mL})=0.008 \mathrm{mg} / \mathrm{mL}$

$[\mathrm{PTZ}]_{\text {soluble }} /[\mathrm{PTZ}-\mathrm{HCP}]_{\text {total }}=(0.008 \mathrm{mg} / \mathrm{mL}) /(2 \mathrm{mg} / \mathrm{mL}) \times 100=0.4 \%$

Similarly, the concentration of the soluble parts in MeCN and DMF can be calculated as 0.2 and $0.6 \%$ of the total network, respectively. 
Table S3. Control experiments using filtrates of PTZ-CMP in different solvents showing no polymerization occurring in the presence of the small amounts of the soluble parts dissolved form PTZ-CMP ${ }^{a}$

\begin{tabular}{lllrrrr}
\hline Entry & Ligand & Solvent $^{b}$ & Conversion (\%) & $M_{\mathrm{n}, \mathrm{th}}$ & $M_{\mathrm{n}}$ & $\oplus$ \\
\hline 1 & PMDETA & DMSO & 0 & - & - & - \\
2 & Me6TREN & DMF & 0 & - & - & - \\
3 & Me6TREN & MeCN & 0 & - & - & -
\end{tabular}

${ }^{a}$ Reaction conditions: $[\mathrm{MA}] /[\mathrm{EBiB}] /\left[\mathrm{CuBr}_{2}\right] /[\mathrm{L}]=200 / 1 / 0.04 / 0.2$ (solvent $50 \mathrm{vol} \%$ ) under green

light irradiation $\left(520 \mathrm{~nm}, 9 \mathrm{~mW} / \mathrm{cm}^{2}\right)$ for $24 \mathrm{~h} .{ }^{b}$ PTZ-CMP was stirred in each solvent (2 $\mathrm{mg} / \mathrm{mL}$ ) for $24 \mathrm{~h}$ and was filtered off using syringe filters to remove the heterogeneous parts, leaving transparent solutions which were used as solvents for ATRP. 

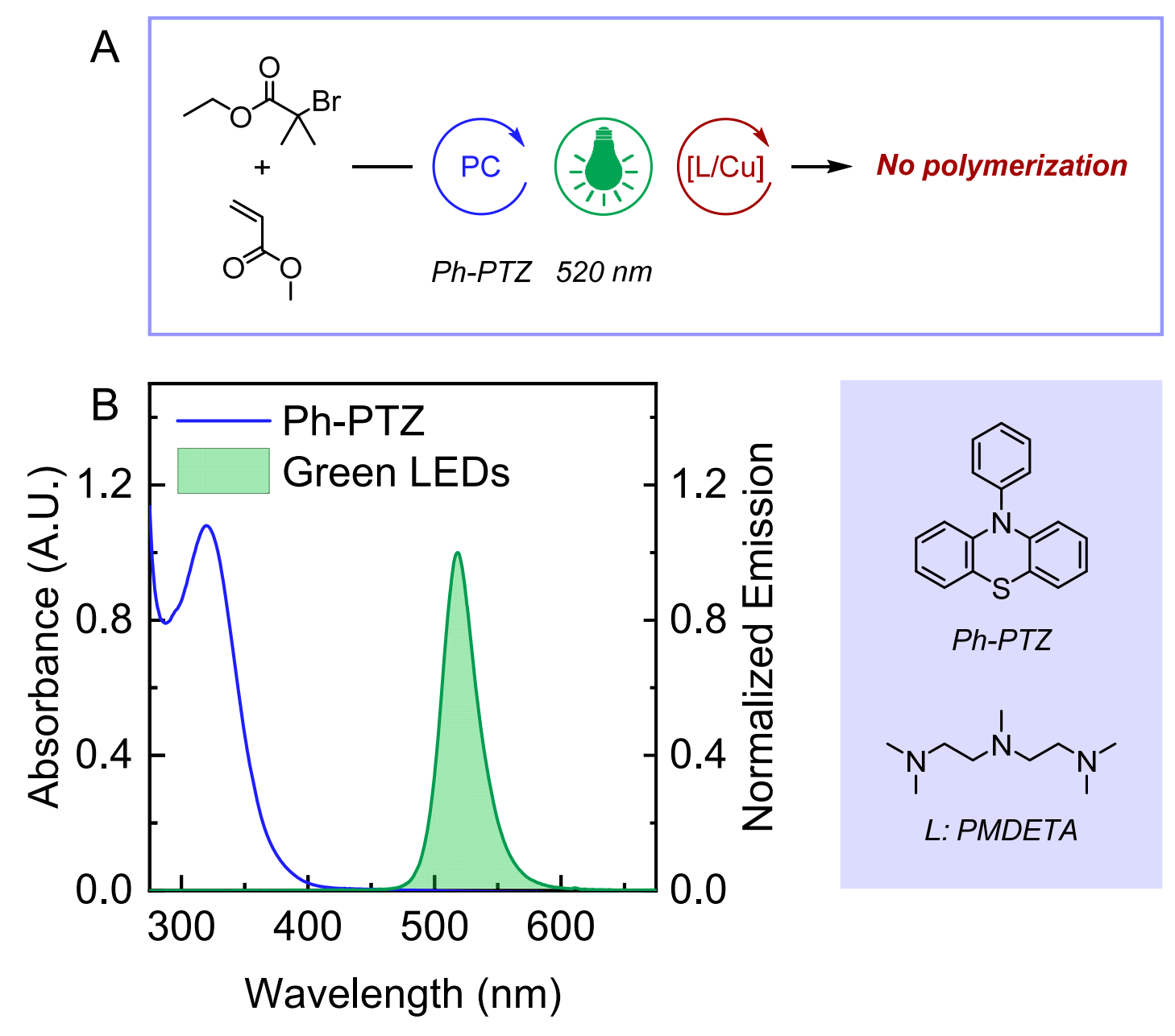

Figure S12. (A) Control experiment in the presence of $\mathrm{Ph}-\mathrm{PTZ}$ as a photocatalyst that resulted in no polymerization of MA under green light irradiation. (B) UV-vis spectra of Ph-PTZ showing absorbance in the UV region $<400 \mathrm{~nm}$ with no overlap with the emission spectra of the green LEDs ([Ph-PTZ] $=0.02 \mathrm{mM}$ in DMSO). Reaction conditions: $[\mathrm{MA}] /[\mathrm{EBiB}] /\left[\mathrm{CuBr}_{2}\right] /[\mathrm{PMDETA}]=200 / 1 / 0.04 / 0.12$ in DMSO (50 vol\%), Ph-PTZ = 5 or $10 \mathrm{mg} / \mathrm{mL}$ (18 or $36 \mathrm{mM}$, respectively), irradiated under green light (520 nm, 9 $\left.\mathrm{mW} / \mathrm{cm}^{2}\right)$ for $24 \mathrm{~h}$. 
Recycling experiments:
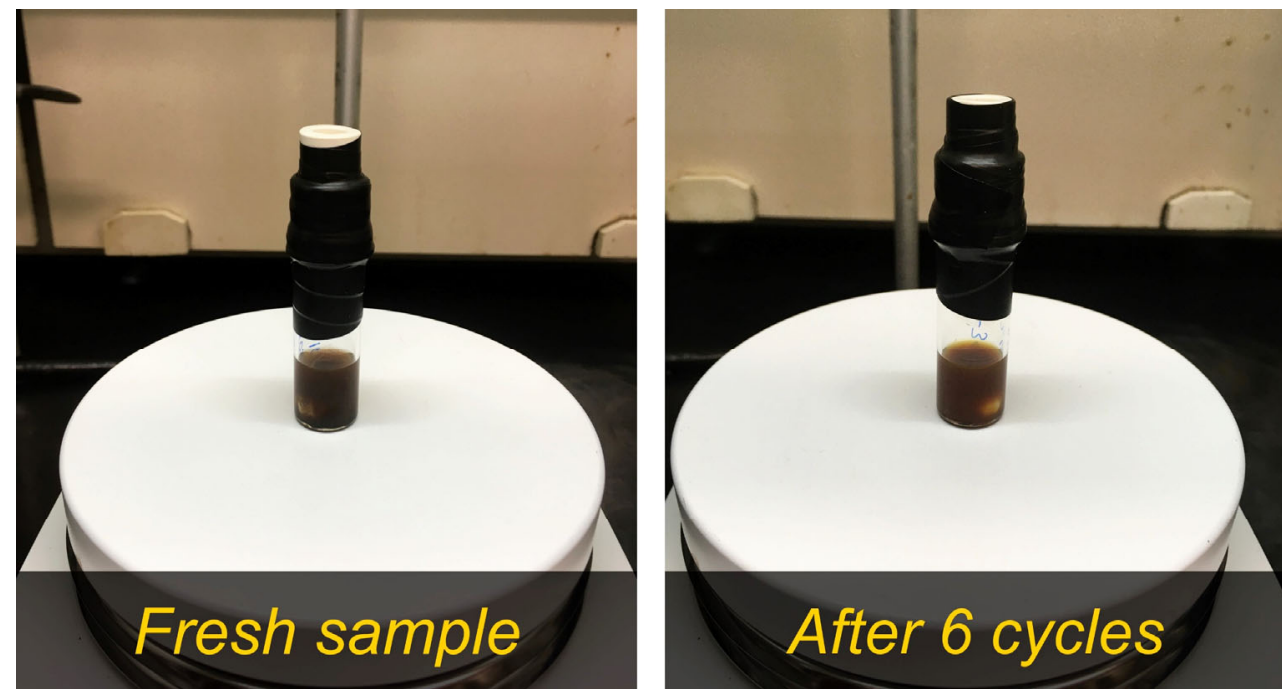

Figure S13. Photographs of the polymerization solution before (fresh) and after recycling experiments ( 6 cycles).

ATRP of MMA:
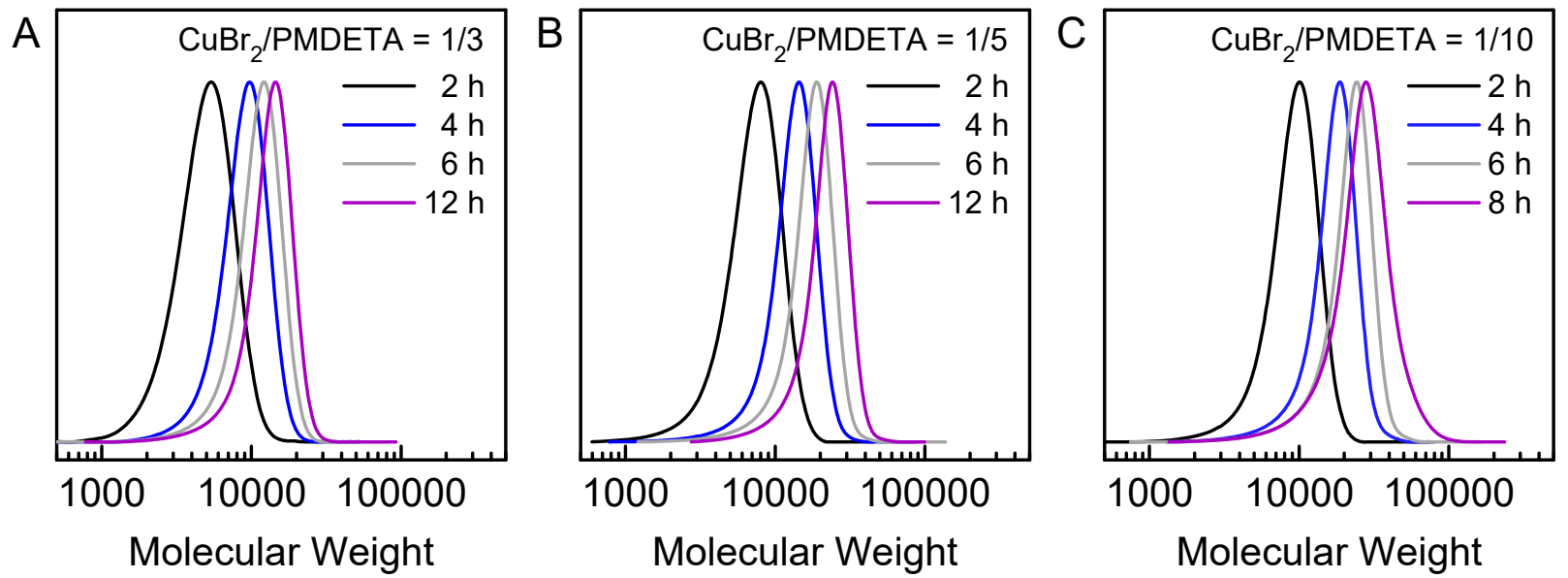

Figure S14. SEC traces for PMMA synthesized using PTZ-CMP as a photocatalyst in the presence of different concentrations of excess PMDETA as electron donor. Reaction conditions: $[\mathrm{MMA}] /[\mathrm{EBPA}] /\left[\mathrm{CuBr}_{2}\right] /[\mathrm{PMDETA}]=200 / 1 / 0.04 / \mathrm{x}(\mathrm{x}=0.12,0.2$, and 0.4 ) in DMSO (50 vol\%) under green light irradiation $\left(520 \mathrm{~nm}, 9 \mathrm{~mW} / \mathrm{cm}^{2}\right)$, PTZ$\mathrm{CMP}=2 \mathrm{mg} / \mathrm{mL}$. 


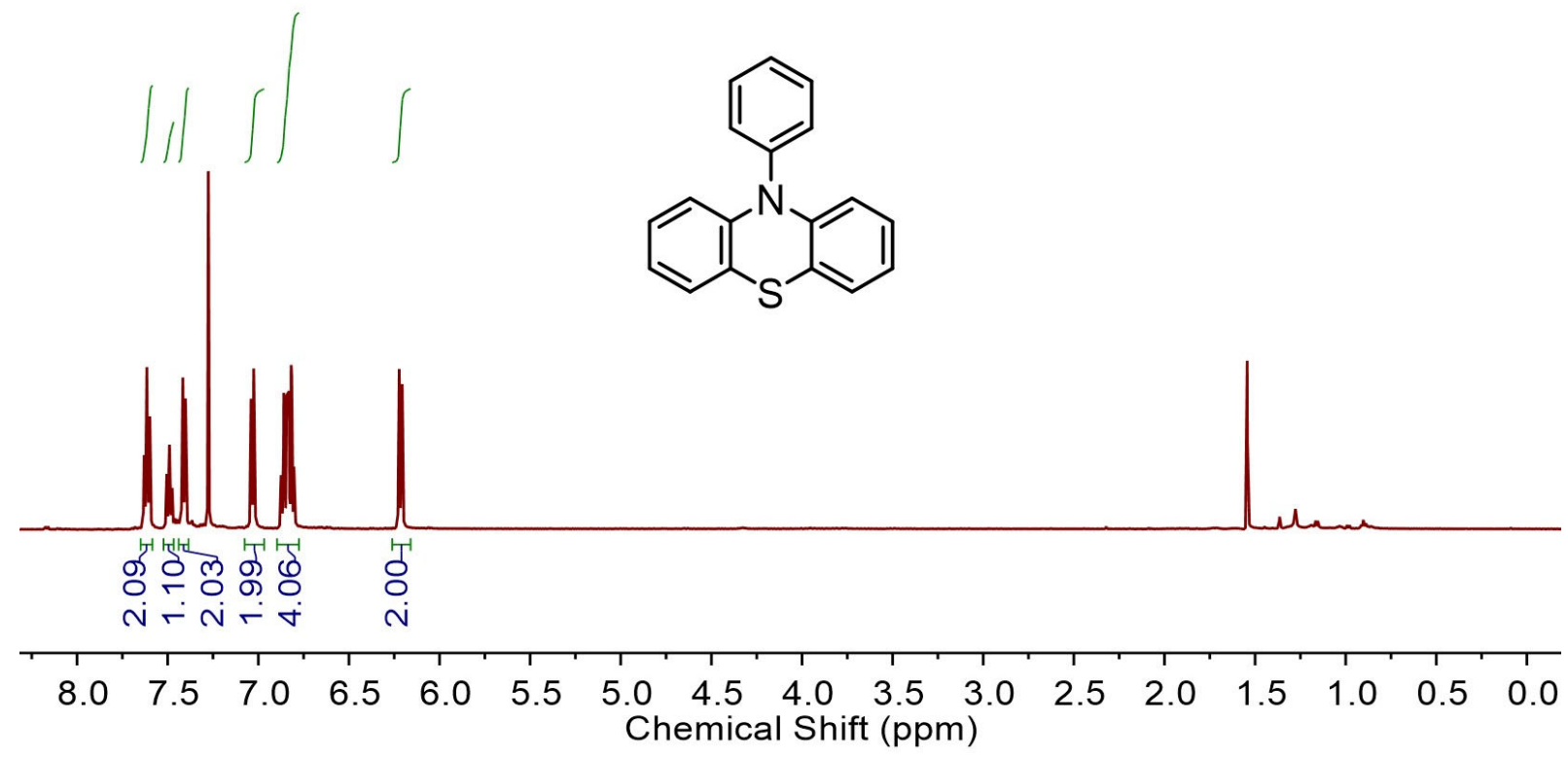

Figure S15. ${ }^{1} \mathrm{H}$ NMR spectra of Ph-PTZ recorded in deuterated chloroform. 